\title{
Microstructure and Wear Behavior of Cermet/Iron Alloy Cladding Layers on A6061 Alloy Coated by Resistance Seam Welding Method
}

\author{
Wen-Qin Wang • Tomiko Yamaguchi • Kazumasa Nishio
}

Received: 23 June 2014/Revised: 19 September 2014/Published online: 5 February 2015

(C) The Chinese Society for Metals and Springer-Verlag Berlin Heidelberg 2015

\begin{abstract}
Cermet/iron alloy cladding layers were coated on the surface of Al-Mg-Si alloy (A6061) plates by resistance seam welding method with tungsten carbide (WC) and high-carbon iron alloy (SHA) powders. The cladding layer consisted of $\mathrm{WC}$ reinforcement, SHA binder, $\mathrm{A} 6061$ and $\mathrm{FeAl}_{3}$. The effect of $\mathrm{WC}$ ratio (30 wt $\%, 50 \mathrm{wt} \%$ and $70 \mathrm{wt} \%$ ) on the microstructure and wear behavior of the cladding layers was investigated in detail. Abrasive wear test was performed under two kinds of load condition by using a rubber wheel apparatus to evaluate wear resistance. The results showed that the wear resistance of the cladding layer was improved by 3.5-5 times than that of the substrate. At lower load, the wear resistances of the samples 30\% and 70\% WC were nearly the same, which suggested that $\mathrm{FeAl}_{3}$ played an important role in improvement of the wear resistance instead of WC. While at higher load, the amount of WC determined the wear resistance of the cladding layer. Furthermore, wear behavior of these cladding layers was explained with reference to the observed microstructure of the worn surface.
\end{abstract}

KEY WORDS: Resistance seam welding; A6061; WC; Cladding layer; Wear resistance

\section{Introduction}

Aluminum and its alloys have been widely used in many engineering applications such as automotive and aerospace because of their low density, high specific strength, good electric and thermal conductivity and good corrosion resistance. However, the surface properties of the aluminum alloys, the wear resistance in particular, are not qualified for recent requirements [1]. Laser surface alloy technology [2-4] is a most widely used method for the surface modification of aluminum and its alloys. This

Available online at http://link.springer.com/journal/40195

W.-Q. Wang · T. Yamaguchi $(\bowtie)$

Faculty of Engineering, Kyushu Institute of Technology,

Fukuoka 804-0015, Japan

e-mail: yama@tobata.isc.kyutech.ac.jp

K. Nishio

Nishinippon Institute of Technology, Fukuoka 803-0812, Japan technique could produce good wear-resistant layers in the order of millimeters within short time by using high energy density heat source. However, the high heat generation of laser could affect the internal properties of thin substrates owing to the low melting point of aluminum alloys, so it is still a challenge to prepare the cladding layer on thin aluminum alloy plate.

Therefore, it is very attractive to produce wear resistance cladding layer with high thickness on the surface of thin aluminum plate with low processing heat. Resistance seam welding (RSEW) method is an efficient plate-plate joint method, which can be processed under relative lower heat. Therefore, RSEW method could be used as a surface treatment technology for aluminum alloys. In fact, we have proved that the wear resistance cladding layer was easily coated on the surface of SPCC by this method in our previous study [5].

Using powders as wear resistance material, the thickness of the cladding layer could be easily controlled by adjusting the amount and size of the powders. On the 
other hand, the powders, with high specific surface energy, can adhere to aluminum alloy substrate easily even with low heat. WC cermet is one of the most popular wear resistance material applied in many machinery industries, due to its advantages of high hardness, low coefficient of friction, good plasticity and wettability by molten metals [6-10]. Moreover, iron-based alloys have the merits of low cost, versatility, good electric conductivity and good wear resistance [11], which is usually used as binders for WC particles.

In this research, we chose tungsten carbide (WC) powders as reinforcement and high-carbon iron alloy (SHA) powders as binder material and wear resistance material and the RSEW method as the surface treatment technology to fabricate cermet/iron alloy cladding layers on the surface of A6061 alloy. Furthermore, the effects of the cermet ratio (30 wt $\%, 50 \mathrm{wt} \%$ and $70 \mathrm{wt} \%$ ) in the weld powders on microstructure and wear behavior of the cladding layers were also investigated in detail.

\section{Experimental}

\subsection{Materials}

The Al-Si-Mg alloy (A6061) of $2 \mathrm{~mm} \times 30 \mathrm{~mm} \times$ $150 \mathrm{~mm}$ was used as the substrate plate. WC and SHA powders, mixed in weight ratio of 3:7, 1:1 and 7:3 (marked as $30 \%, 50 \%$ and $70 \%$ WC) were used as the cladding materials. The diameters of WC particles were in the range of $45-75 \mu \mathrm{m}$ and those of the SHA powders were in the range of $60-90 \mu \mathrm{m}$ as shown in Fig. 1. The chemical compositions of SHA powders are shown in Table 1.
Table 1 Chemical composition of SHA powders (wt\%)

\begin{tabular}{llllll}
\hline $\mathrm{Fe}$ & $\mathrm{Cr}$ & $\mathrm{C}$ & $\mathrm{Mo}$ & $\mathrm{Ni}$ & $\mathrm{Si}$ \\
\hline Bal. & 9.84 & 4.99 & 4.92 & 4.83 & 0.99 \\
\hline
\end{tabular}

\subsection{Resistance Seam Welding Process}

First, the A6061 surface was polished by emery paper (No. 240) to remove the oxides and cleaned with acetone; then, the mixed powders were pre-placed on the surface of the substrate with dimension of $0.8 \mathrm{~mm} \times 5 \mathrm{~mm} \times 50 \mathrm{~mm}$ using organic binders as shown in Fig. 2a and then dried for $4 \mathrm{~h}$ at room temperature. Figure $2 \mathrm{~b}$ shows the process of resistance seam welding. The electrodes had dimensions of $65 \mathrm{~mm}$ in diameter and $5 \mathrm{~mm}$ in width. A SUS304 foil with thickness of $100 \mu \mathrm{m}$ was placed on the powder layer to protect the electrodes. When the sample passed and stayed in constant contact with two rotating electrodes, a long continuous weld was formed on the sample because of the Joule heat. The cladding layers were formed on the surface of A6061 plate after welding. The welding condition is given in Table 2 .

\subsection{Experimental Methods}

Microstructural examinations of the cladding layers were carried out by using scanning electron microscope (SEM, EMR-8800, Elionix, Japan) and electron probe microanalyzer (EPMA, JXA-8530F, JEOL, Japan). To investigate wear behavior, the worn surface was examined with three-dimensional scanning electron microscope (3D-SEM, EMR-8800, Elionix, Japan) and field-emission scanning
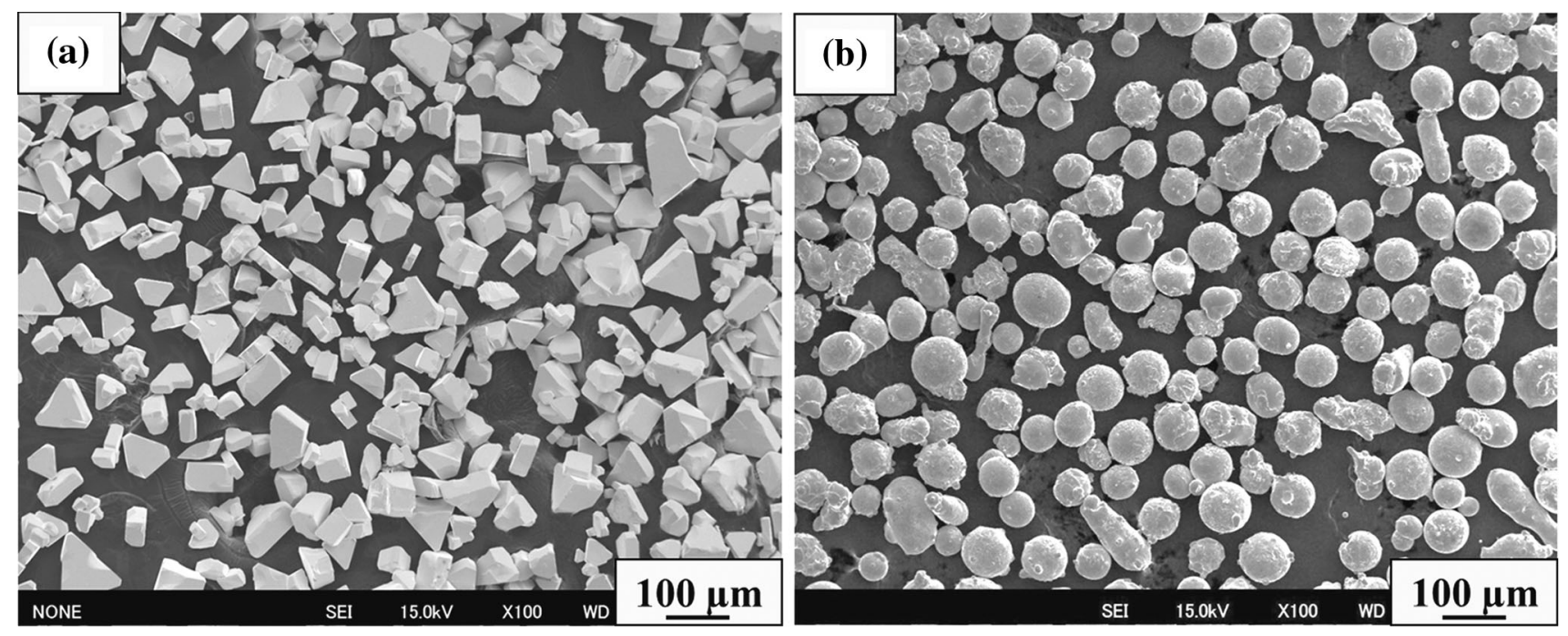

Fig. 1 SEM images of the premixed precursor powders: a WC, b SHA 
(a)

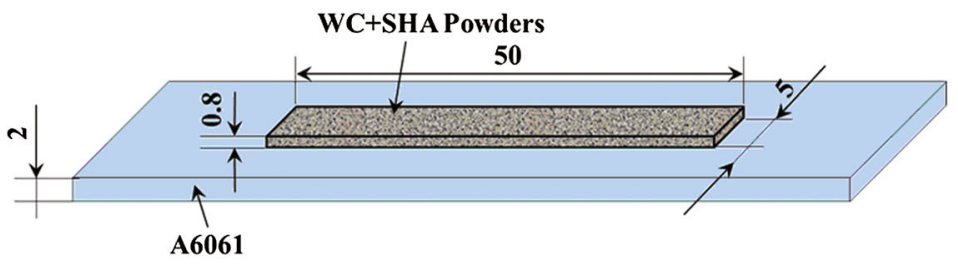

(b)

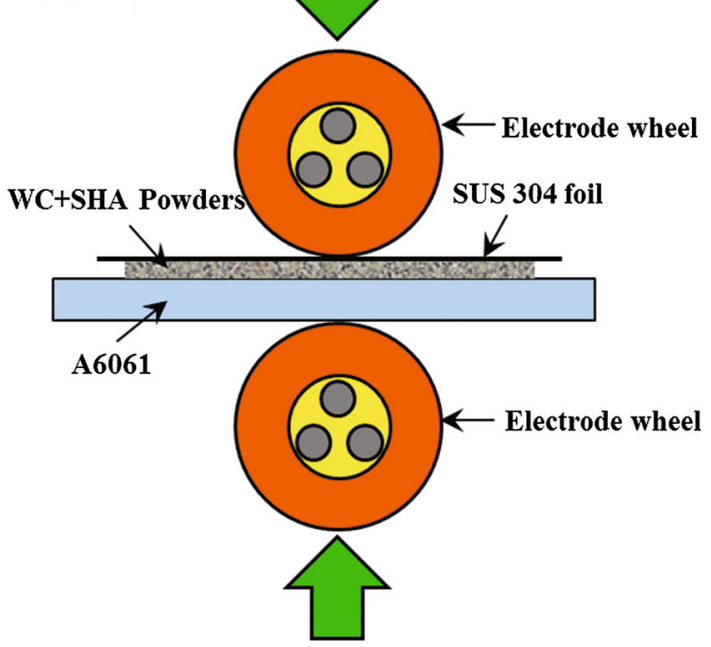

Fig. 2 a Schematic diagram of the sample b resistance seam welding method

Table 2 Conditions of resistance seam welding

\begin{tabular}{lll}
\hline $\begin{array}{l}\text { Welding speed } \\
(\mathrm{m} / \mathrm{min})\end{array}$ & $\begin{array}{l}\text { Electrode force } \\
(\mathrm{N})\end{array}$ & $\begin{array}{l}\text { Welding current } \\
(\mathrm{kA})\end{array}$ \\
\hline 0.5 & 98 & 3.0 \\
\hline
\end{tabular}

electron microscopy (FE-SEM, JSM-6701, JEOL, Japan) combined with energy dispersive spectroscopy (EDS).

Wear resistance of the cladding layer was evaluated by an abrasive wear test using a rubber wheel apparatus. Figure 3 shows the schematic diagram of the abrasion test and specimen, and measurement of the abrasion depth. The rubber cylinder with an external diameter of $250 \mathrm{~mm}$ and thickness of $25 \mathrm{~mm}$ was used as a rotating counter roller. The tests were carried out at loads of 3.64 and $23.5 \mathrm{~N}$, respectively. During the tests, silica sands $(200-400 \mu \mathrm{m})$ were dropped onto the interface between the sample and the rubber wheel with a speed of $300-350 \mathrm{~g} / \mathrm{min}$. The rotational speed of the cylinder was $180 \mathrm{~m} / \mathrm{s}$ and rotational number was 1,000 r (see Fig. 3a). Figure $3 \mathrm{~b}$ shows the schematic diagram of specimen for rubber wheel test. The A6061 coated with and without cladding layers were cut into stripes of $40 \mathrm{~mm} \times 2.5 \mathrm{~mm}$ and then set on the mild steel SS400 with dimension of $8 \mathrm{~mm} \times 20 \mathrm{~mm} \times 40 \mathrm{~mm}$ by using organic binders. The depth of material loss after wearing was measured as shown in Fig. 3c. (a)

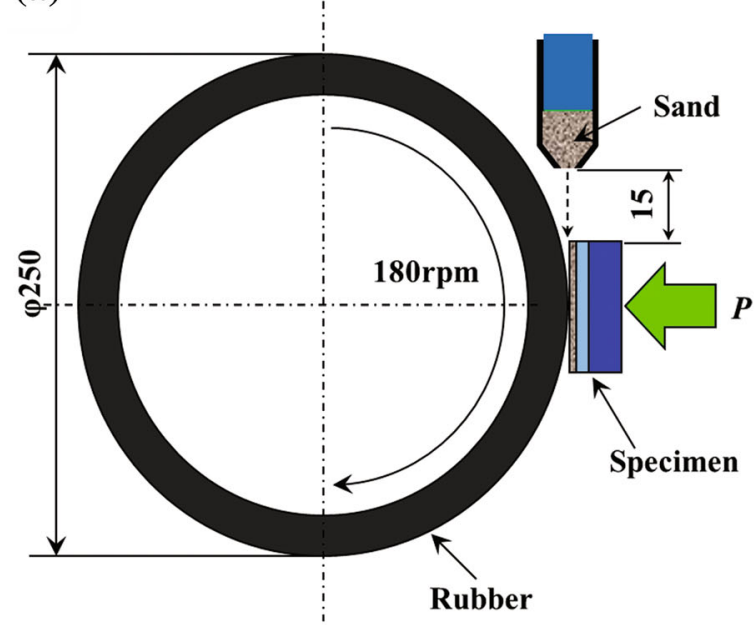

(b)
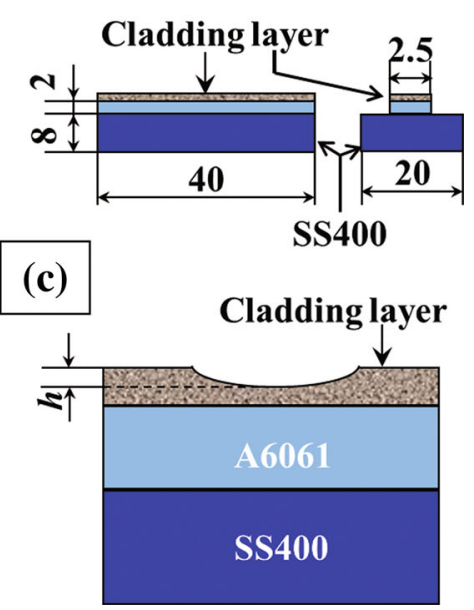

Fig. 3 a Schematic diagram of the rubber wheel test, $\mathbf{b}$ schematic diagram of specimen for rubber wheel test, $\mathbf{c}$ measurement of the abrasion depth 


\section{Results and Discussions}

\subsection{Microstructural Characteristics}

\subsubsection{Scanning Electron Microscopy}

The cross-sectional microstructures of the samples formed with three different ratios of WC powders are shown in Fig. 4. The cladding layers fabricated with different $\mathrm{WC}$ ratios had the same thickness of about $600 \mu \mathrm{m}$. The WC particles (white) with irregular shape and microsphere SHA particles (gray) were clearly observed in these cladding layers. The SHA powders in all samples were not dissolved during the welding process, which kept the same shape and dimension with the raw powders. Besides, molten A6061 (black) among these mixed particles could be observed, indicating that the surface of the A6061 substrate was partially melted and then penetrated into the cladding layer through capillary action. The amount of molten A6061 in the cladding layer decreased with the increase in WC ratio. Moreover, the cladding layer/substrate interfaces had no visible cracks or delamination, implying that the cladding layer and substrate were well bonded. However, a small number of micro-porosities that existed in the cladding layers may be attributed to a rapid melting and solidification, because the heat generated quickly and the interaction time was extremely short in the welding process. Previous work showed that WC particles tended to sink to the bottom of the cladding layer, as a result of a stirring motion in the melted pool [12]. However, in this study, the tendency was not observed in all samples. The viscosity and solidification rate of the molten A6061 played a vital role in the uniform distribution of WC powders, and this result had a positive effect on wear resistance of the cladding layers. From Fig. 4a-c, we can conclude that the cermet/iron alloy cladding layers were successfully fabricated on the A6061 alloys by the RSEW method.

Another interesting feature observed from the enlarged view near surface region of these cladding layers (see Fig. 5d-f) was that some precipitations were formed in the molten A6061 alloy. Besides, the morphology of the precipitations of the sample $70 \%$ WC changed from bulk to coarse needle-like, and finally fine needle-like structure. Moreover, the amount of these precipitations declined with the increase in the ratio of WC. The formation of the precipitations was the consequence of the reaction between added powders and molten A6061, and these differences in microstructure of the precipitations were probably due to the different heat generation in these samples.

\subsubsection{Electron Probe Micro-analyzer Mapping and X-ray Diffraction Analysis}

EPMA mapping images at near surface and bottom regions of the sample consisting of 50\% WC are shown in Figs. 5 and 7. Figure 5 shows a duplication area of $\mathrm{Fe}$ and $\mathrm{Al}$ elements with needle-like morphology in the molten A6061 corresponding to the precipitations mentioned in Fig. 4. The formation and growth of $\mathrm{Fe}-\mathrm{Al}$ phase in solid iron and liquid aluminum were explained by reaction diffusion laws in several studies [13-16]. When the surface of the A6061 alloy melted and started to contact with SHA powders in the welding process, Fe from SHA powders diffused into molten A6061 to form the Al-rich phase such as $\mathrm{Fe}_{2} \mathrm{Al}_{5}$ and $\mathrm{FeAl}_{3}$ because the diffusion coefficient of iron into aluminum is much greater than that of aluminum into iron [17]. Furthermore, according to the thermodynamic principles, the standard Gibbs free energy to form $\mathrm{Fe}_{2} \mathrm{Al}_{5}$ is higher than $\mathrm{FeAl}_{3}$ [18], so the formation of $\mathrm{FeAl}_{3}$ was prior to the formation of $\mathrm{Fe}_{2} \mathrm{Al}_{5}$. In other words, the precipitations in the cladding layer could be considered to be $\mathrm{FeAl}_{3}$ and the bulk and needle-like structure of $\mathrm{FeAl}_{3}$ were also in agreement with previous works $[19,20]$. Moreover, $\mathrm{W}$ and $\mathrm{C}$ elements were uniformly distributed in the WC particles. It is reasonable to consider that WC did not decompose to $\mathrm{W}_{2} \mathrm{C}$ and $\mathrm{C}$ phases [21] because of low heat generation during the welding process.

Furthermore, an extensive effort was undertaken to find out the intermetallic compound of $\mathrm{Fe}$ and $\mathrm{Al}$ by XRD analysis. The X-ray diffraction pattern of the near surface region prepared in the sample 50\% WC is shown in Fig. 6. The $\mathrm{Fe}-\mathrm{Al}$ intermetallic phase of $\mathrm{FeAl}_{3}$ was identified in the cladding layer. Moreover, other phases such as $\mathrm{W}_{2} \mathrm{C}$ and $\mathrm{W}$ were not identified, which was in agreement with the results of EPMA.

Compared with the near surface region of the cladding layer, $\mathrm{Fe}$ and $\mathrm{Al}$ element distributions at the bottom region were obviously different as shown in Fig. 7. Fe was not observed in the molten A6061, which implied that $\mathrm{FeAl}_{3}$ did not form on the bottom of the cladding layer. The difference was probably related to the deposition of SUS304 with high electrical resistance on the surface of the powder layer, and thus led to higher heat generation on the surface than the bottom region. Similar results were obtained from the samples consisting of $30 \%$ and $70 \%$ WC.

\subsection{Wear Behaviors}

\subsubsection{Abrasive Wear Test}

In order to evaluate the durability of the samples, the abrasive wear test was carried out at two different load conditions. Table 3 shows the average abrasion depths of the A6061 substrate with and without cladding layers after abrasive wear test at load of 3.64 and $23.5 \mathrm{~N}$. This is also depicted in Fig. 8. Figure 8 clearly shows that the average abrasion depths with the cladding layers were significantly lower than that of the A6061 substrate without cladding 

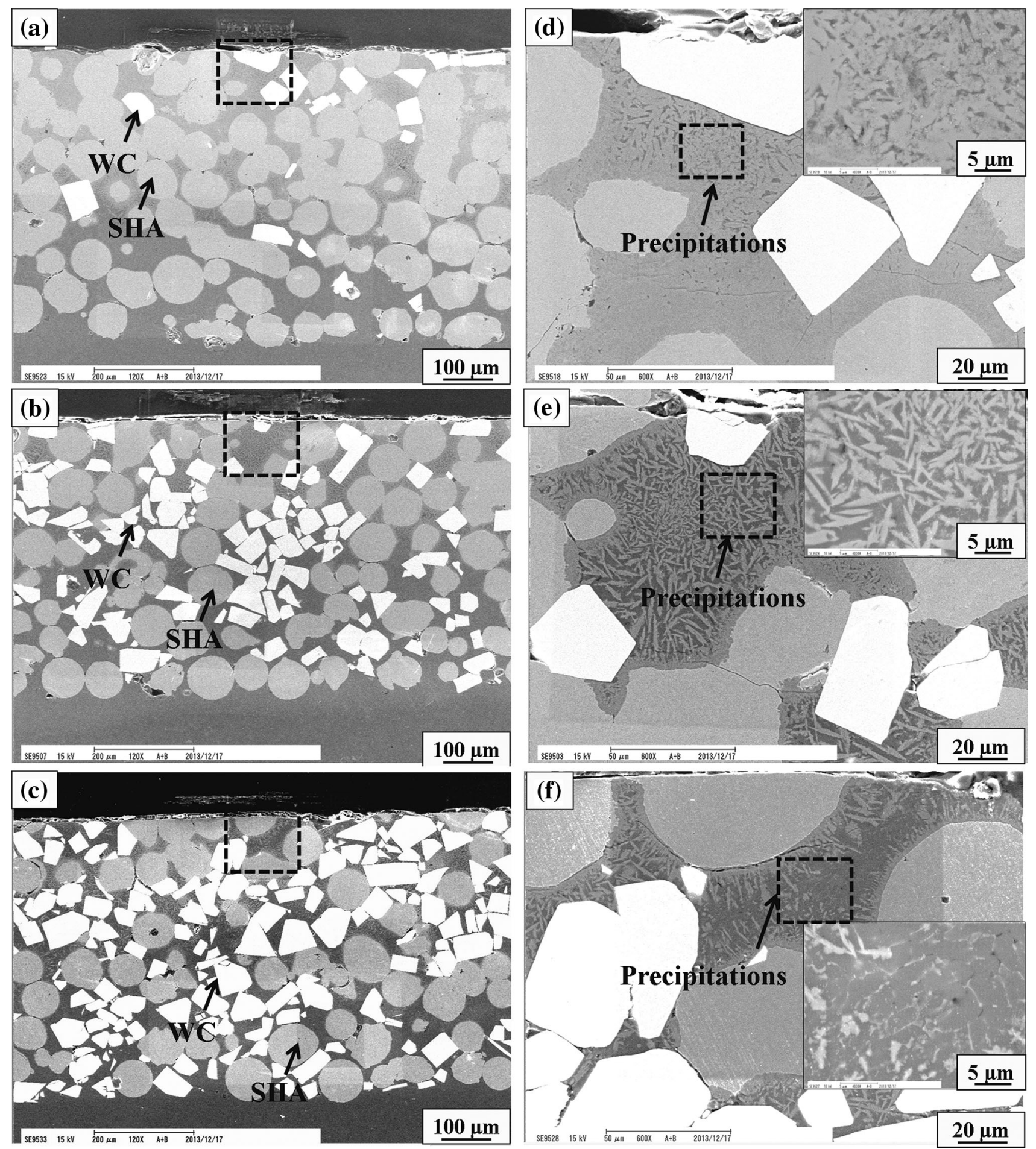

Fig. 4 SEM images of the cladding layers on the cross section: a $30 \% \mathrm{WC}, \mathbf{b} 50 \% \mathrm{WC}, \mathbf{c} 70 \% \mathrm{WC}, \mathbf{d}, \mathbf{e}, \mathbf{f}$ enlarged view near surface region in a, b, c, respectively

layers. At the load of $3.64 \mathrm{~N}$, the wear resistance improvement of the samples consisting of $30 \%, 50 \%$ and $70 \% \mathrm{WC}$ were 4.7, 3.5 and 4.8 times than the A6061 substrate. While at higher load, the wear resistance increased 3.5, 3.6, and 4.1 times, respectively. The abrasive loss of the samples with cladding layers was 3.5-5 times less than the substrate. Apparently, the cladding layers exhibited more excellent wear resistance at low load than high load. Moreover, the optimum wear resistance was obtained from the sample consisting of $70 \%$ WC. This result was in accordance with 

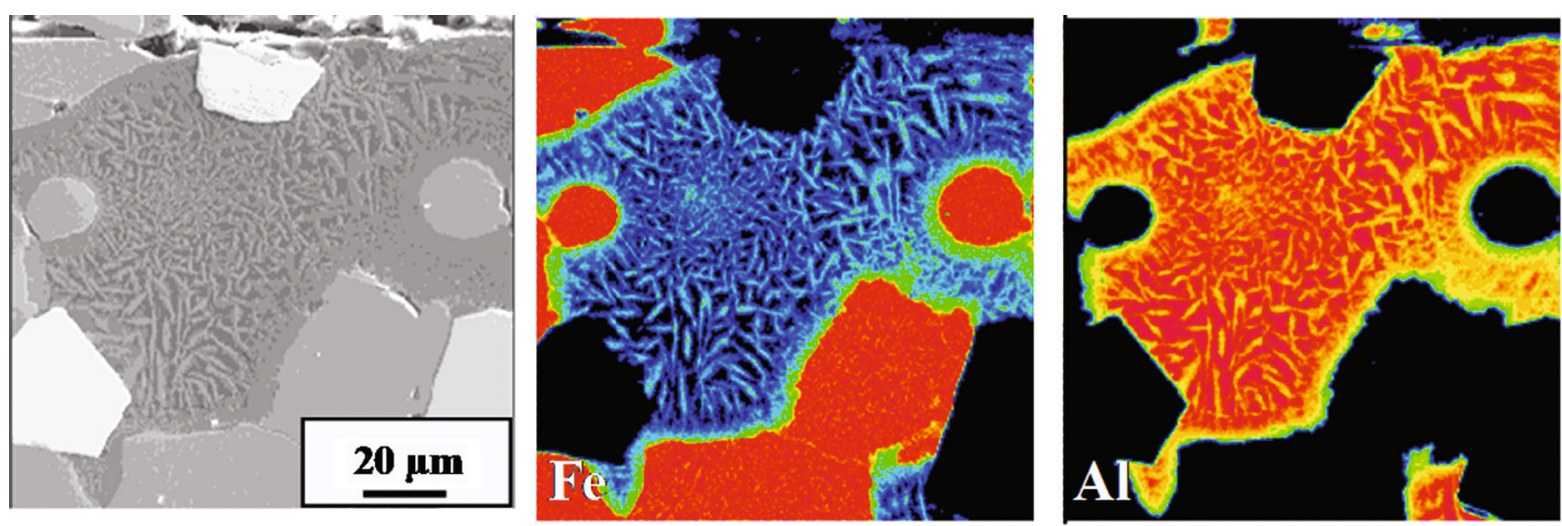

high
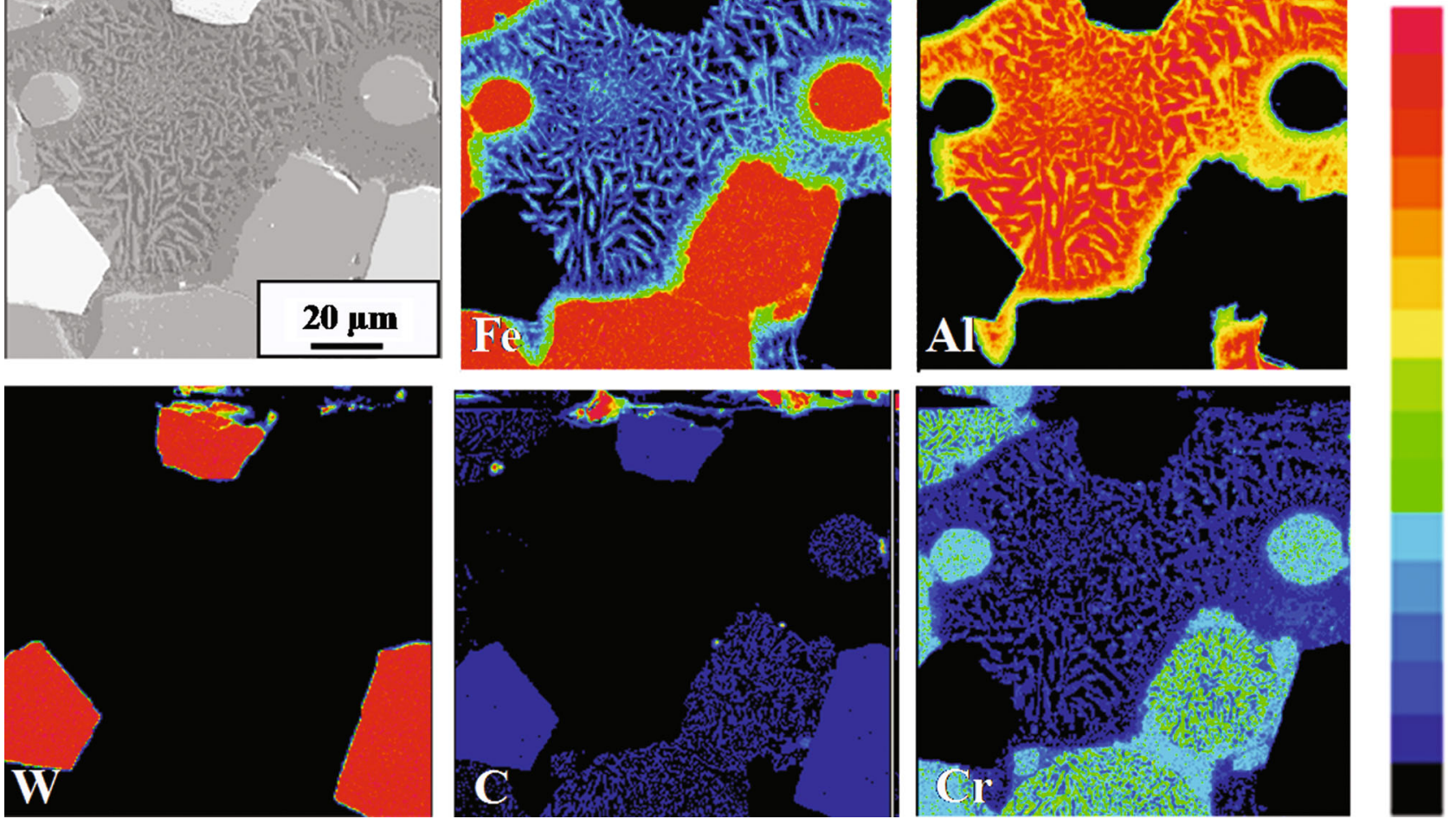

Fig. 5 EPMA mapping images of the sample consisting of 50\% WC at near surface region

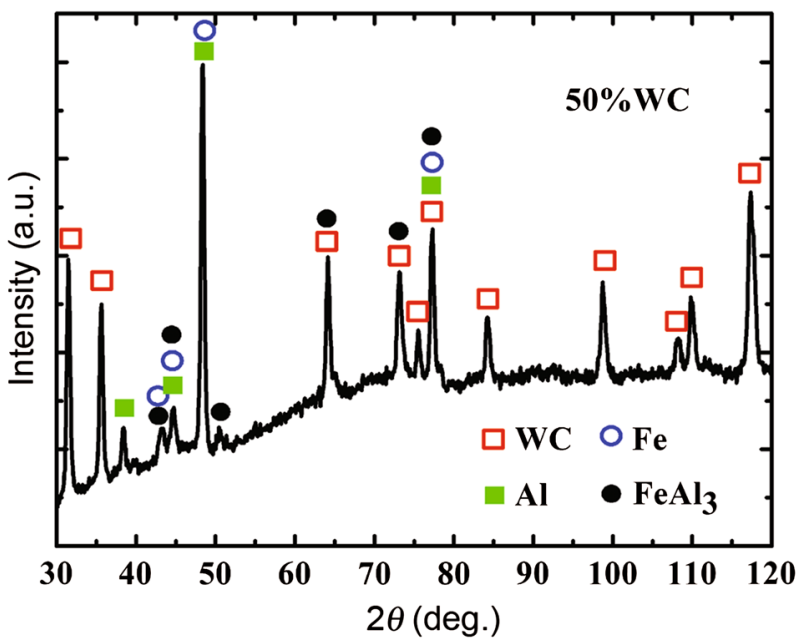

Fig. 6 XRD analysis results of the sample consisting of 50\% WC

the fact that the wear resistance of the cladding layer improved with the increase in the amount of reinforcement. However, in spite of the dominant powders being changed from SHA particles to WC particles, the samples consisting of $30 \%$ and $70 \%$ WC showed similar wear resistance at low load, which indicated that there was another dominant parameter that should be considered to be responsible for the improvement of wear resistance.

\subsubsection{Study of Worn Surface}

The average roughness of the cladding layer before and after wear test is given in Table 4. The roughness values after wear test were obviously greater than the values before wear test for all samples. They increased with the increase in $\mathrm{WC}$ ratio and load. The maximum roughness value was obtained in the sample consisting of $70 \% \mathrm{WC}$ at load of $23.5 \mathrm{~N}$. The surfaces of the samples were prepared by grinding and final polishing with No. 100 emery paper before the wearing test. However, it should be noted that the roughness value (from 0.78 to $1.18 \mu \mathrm{m}$ ) increased with the increase in the $\mathrm{WC}$ ratio before the wear rest.

The worn surfaces before and after wearing tests at load of $3.64 \mathrm{~N}$ were observed by using 3D SEM. The results are shown in Fig. 9. Figure 9a shows that the surface of the cladding layer exhibits a relatively flat geometry and all the components were polished at the same altitude gradient except the WC particles. The altitude gradient of the WC particles was lower than the others, probably because of its characteristics of high hardness and brittleness. This result also explained the reason that the surface roughness value of the samples before wear test increased with increasing the $\mathrm{WC}$ ratio.

In contrast, WC particles possessed a much higher altitude gradient than the other components after wear test 

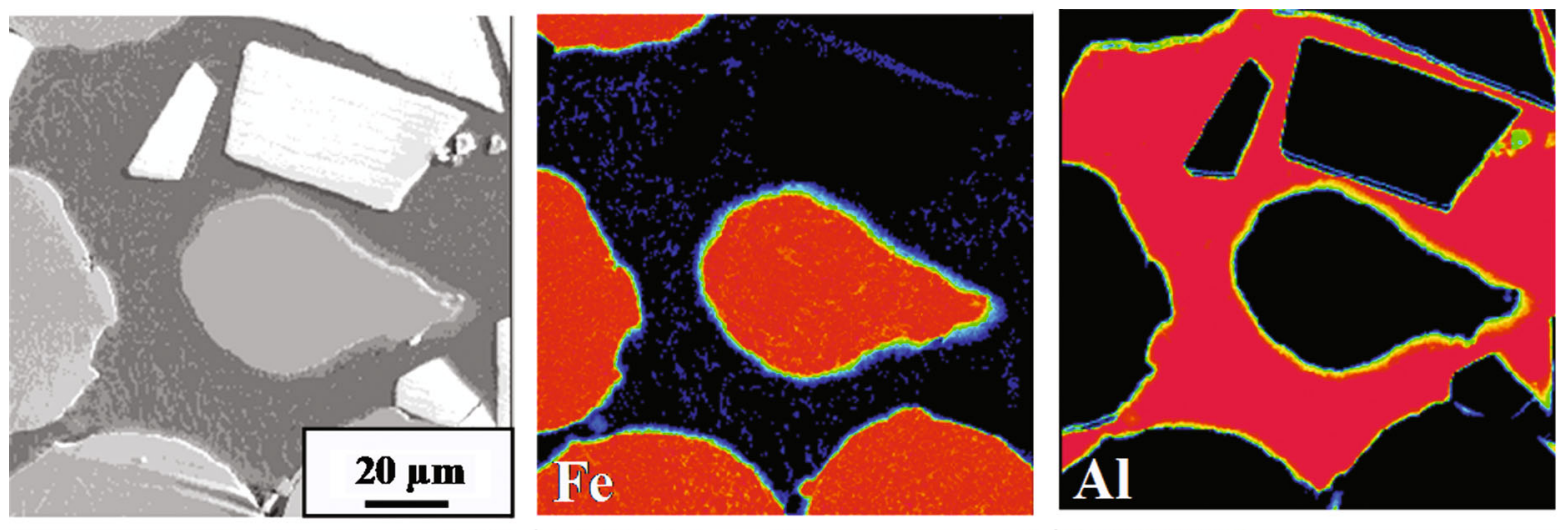

high
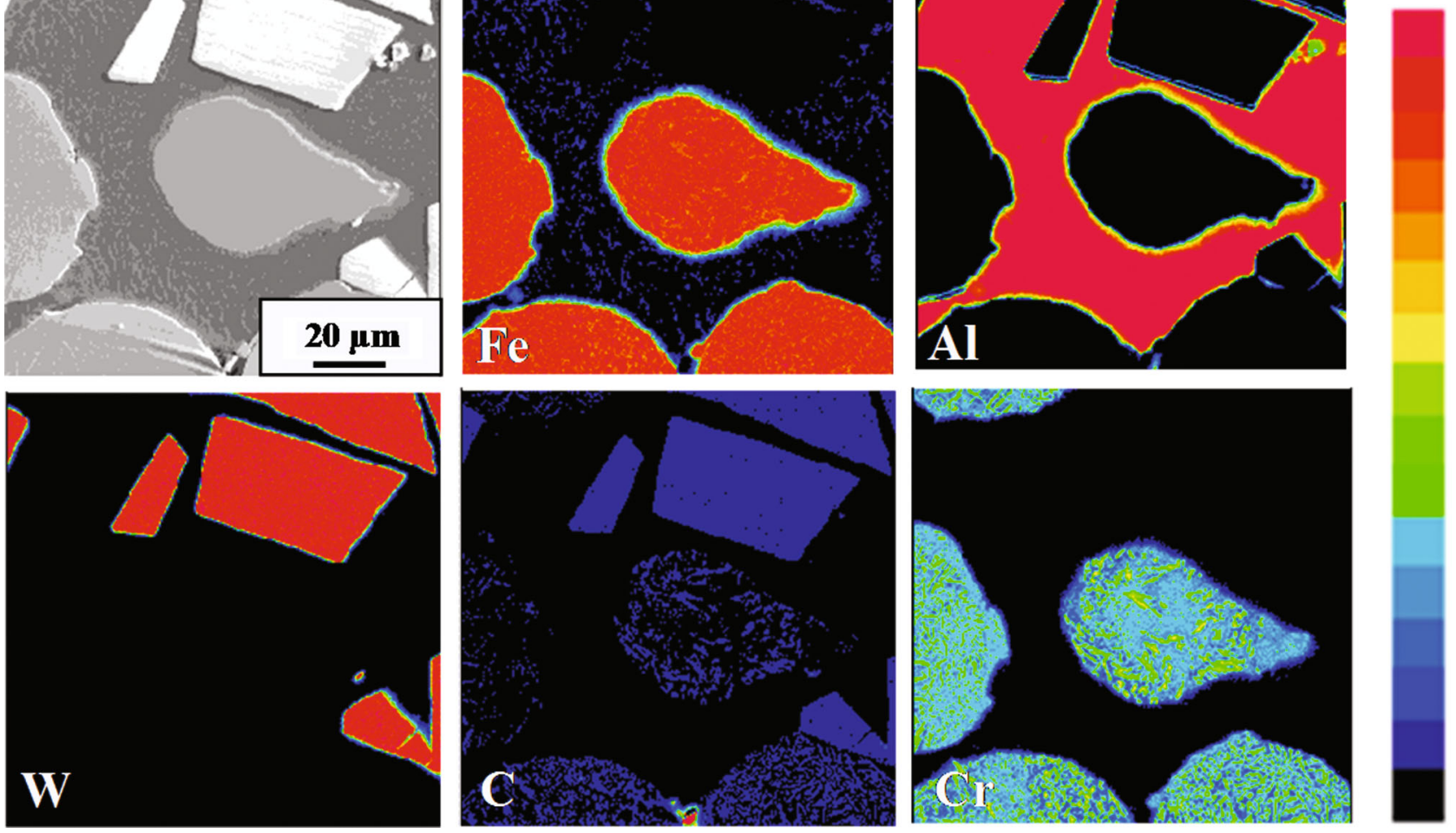

Fig. 7 EPMA mapping images of the sample consisting of 50\% WC at near bottom region

Table 3 Abrasion depth of the substrate and samples tested at different loads

\begin{tabular}{llccc}
\hline Load $(\mathrm{N})$ & \multicolumn{4}{l}{ Abrasion depth $(\mu \mathrm{m})$} \\
\cline { 2 - 5 } & A6061 & $30 \% \mathrm{WC}$ & $50 \% \mathrm{WC}$ & $70 \% \mathrm{WC}$ \\
\hline 3.64 & 216 & 46 & 61 & 45 \\
23.5 & 804 & 230 & 224 & 199 \\
\hline
\end{tabular}

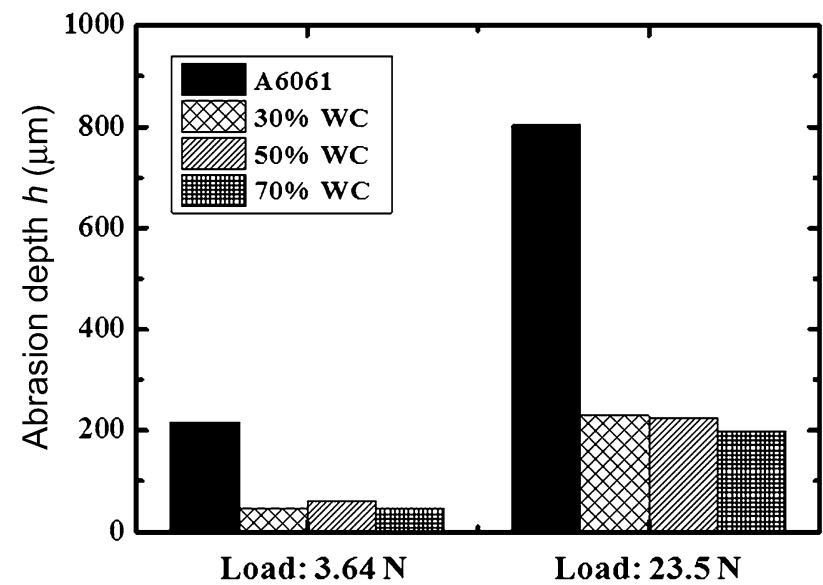

Fig. 8 Abrasion depth of substrate and samples at different loads
Table 4 Average roughness $(\mu \mathrm{m})$ of the cladding layer before and after wear test

\begin{tabular}{llll}
\hline Sample & Before wear test & Load $(3.64 \mathrm{~N})$ & Load $(23.5 \mathrm{~N})$ \\
\hline $30 \% \mathrm{WC}$ & 0.78 & 2.92 & 2.98 \\
$50 \% \mathrm{WC}$ & 1.14 & 3.06 & 3.24 \\
$70 \% \mathrm{WC}$ & 1.18 & 3.09 & 3.60 \\
\hline
\end{tabular}

for the samples consisting of $30 \%$ and $70 \%$ WC (see Fig. 9b, c). The significant difference was a consequence of the abrasive loss of other compositions during the wear test. The images of the samples 30\% and 70\% WC revealed that the penetrated A6061 suffered the greatest damage due to the lowest hardness, while WC with the highest hardness suffered the least damage. However, it should be noted that, in the sample consisting of $30 \% \mathrm{WC}$, the $\mathrm{FeAl}_{3}$ replaced the A6061 component and possessed the same damage as SHA since the height dimension was the same. This was probably because of the $\mathrm{FeAl}_{3}$ phase dispersing homogeneously into the aluminum matrix and hence forming a good wear resistance metal matrix composite among SHA powders $[22,23]$. This could explain that the wear resistance was similar in the samples consisting of 30 and $70 \% \mathrm{WC}$ at low load due to the fact that there were 

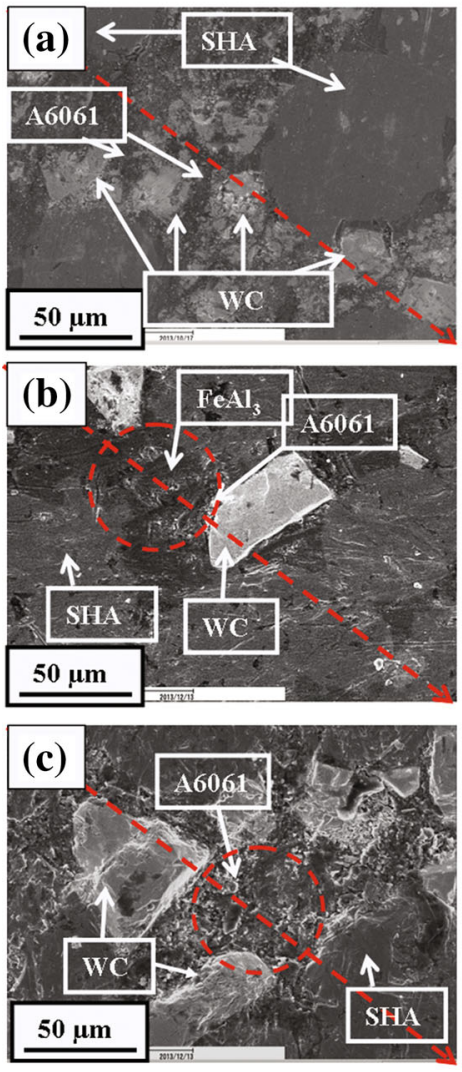
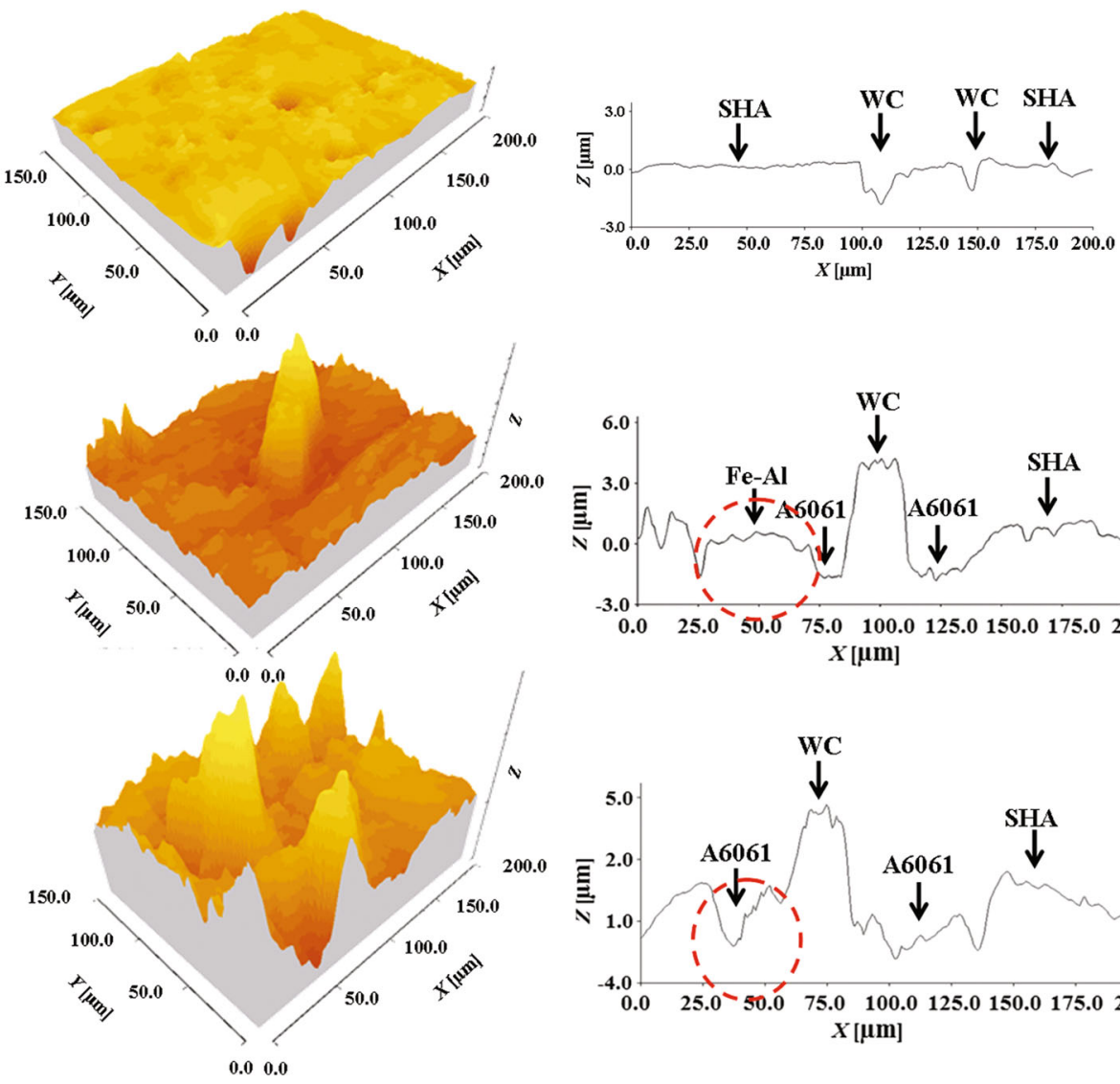
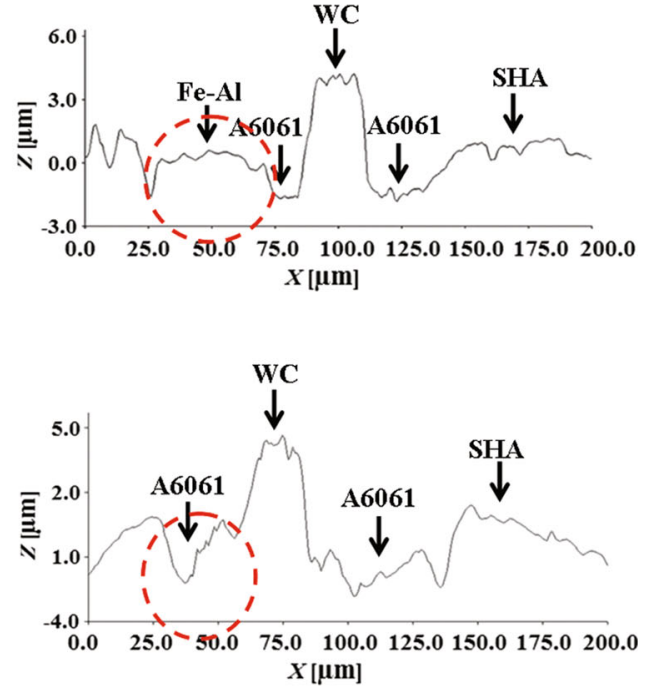

Fig. 9 SEM images, reconstructed 3D-SEM image and corresponding height profile: a surface before wear test in the sample consisting of 70\% WC, b surface after wear test in sample consisting of $30 \%$ WC, c surface after wear test in sample consisting of $70 \%$ WC

more $\mathrm{FeAl}_{3}$ in the sample consisting of $30 \%$ WC which compensated for the reduction in WC powders. Therefore, $\mathrm{FeAl}_{3}$ played an important role in improving wear resistance. In other words, the more the $\mathrm{FeAl}_{3}$ formed in the cladding layers, the better the wear resistance was. However, this beneficial effect could not be maintained at elevated load since $\mathrm{FeAl}_{3}$ disappeared at the bottom of the cladding layer for all the samples. Therefore, at higher load, the wear resistance of the cladding layer increased with the WC ratio because WC particles acted as load support system to prevent the SHA and A6061 from suffering wear damage.

To further examine the worn surface of different components, a high-magnification SEM observation was carried out for the sample consisting of $70 \% \mathrm{WC}$ at load of $3.64 \mathrm{~N}$ as shown in Fig. 10. From Fig. 10a, it can be obviously observed that the main damage and material loss came from delamination. It also indicated that the components observed in this study included the SHA particles (marked as 'b'), junction of $\mathrm{FeAl}_{3}$ and SHA (marked as 'c'), WC particles (marked as 'd') and delamination areas (marked as 'e'). From Fig. 10b, some indentations, shallow scratches and abrasive grooves were observed on the worn surface of SHA component. The abrasive nature was due to hard particles of $\mathrm{SiO}_{2}$ that were forced against and moved along on solid surface of the cladding layer. The indentations were formed by pressing and rotating the $\mathrm{SiO}_{2}$ particles, and the shallow scratches and grooves occurred when the $\mathrm{SiO}_{2}$ particles slid along the surface with pressure, while the former happened at slight pressure and short slid time. However, these scratches and grooves were disordered and were not along the same sliding direction, which was different from the results of other abrasive tests $[24,25]$. The factors such as the size of $\mathrm{SiO}_{2}$ and WC particles as well as the amount and distribution of the WC particles might lead to the difference. These wear damages suggested that wear abrasive mechanism was characterized on the surface of the SHA particles. Furthermore, the SHA particles could be considered as a reinforcement to improve the wear resistance since the depth of the abrasive grooves was shallow and the wear debris was much smaller compared with the delaminated areas. From Fig. 10c, the same result is observed on the surface of $\mathrm{FeAl}_{3}$ phase. Depth and width of the groove on the surface of $\mathrm{FeAl}_{3}$ was as the same as the SHA particles indicating good wear resistance of $\mathrm{FeAl}_{3}$, which was an important contribution to the wear 

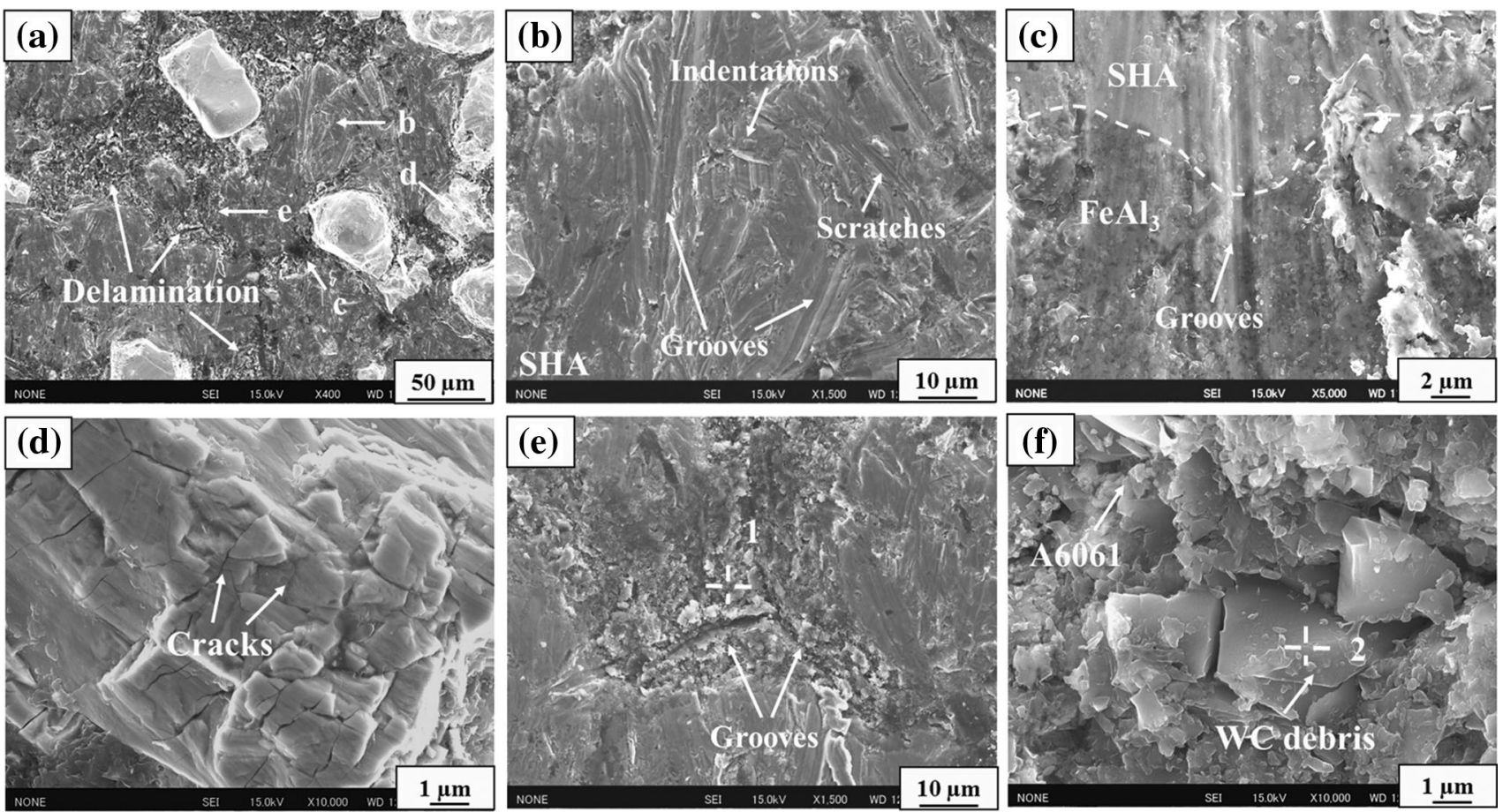

Fig. 10 SEM images of the worn surfaces of different components in the sample consisting of $70 \%$ WC SHA at load of $3.64 \mathrm{~N}$ : a low magnification image, b SHA and $\mathrm{FeAl}_{3}$, $\mathbf{c}$ junction of $\mathrm{FeAl}_{3}$ and SHA, d WC, e delamination area, $\mathbf{f}$ enlarged view in $\mathbf{e}$

resistance of the cladding layer. This result was in accordance with the result in Fig. 9b. Therefore, the slight worn damage of the $\mathrm{FeAl}_{3}$ also provided evidence that the $\mathrm{FeAl}_{3}$ played an important role in improving wear resistance.

In Fig. 10d, there were no visible grooves that could be observed on the surface of the WC particles; a commonly state reason for this was that the hardness of WC was much higher than the abrasive particle $\mathrm{SiO}_{2}$. And thus, the WC powders acted as load support and a main component for resisting wear damages. This result can be also concluded from Fig. $9 b$ and c. However, some nano-cracks on the surface of the WC particles were observed. In the area around these cracks, the WC debris could separate from the WC particles to lead to a brittle failure during wearing. Anyway, this brittle failure did not play an important role in the wear loss of the cladding layer [26, 27].

One of the delamination areas was enlarged as shown in Fig. 10e, which was proved to be A6061 component by point one of EDS analysis in Table 5. Compared with the surface of SHA component, some deeper grooves could be easily observed in the A6061 component. The generation of these grooves was probably related to the fact that $\mathrm{SiO}_{2}$ particles slid along the surface with pressure. From the higher magnification image of the A6061 component in Fig. 10e (see Fig. 10f), the WC debris (identified by the second point of EDS analysis in Table 5) with a size of about $5 \mu \mathrm{m}$ could be observed. These trapped WC debris
Table 5 Results of EDS analysis in Fig. 9e, f (wt\%)

\begin{tabular}{lllllll}
\hline Element & $\mathrm{C}$ & $\mathrm{Al}$ & $\mathrm{W}$ & $\mathrm{Fe}$ & $\mathrm{Ni}$ & $\mathrm{Cr}$ \\
\hline Point 1 & 5.18 & 54.57 & 30.00 & 6.98 & 1.15 & 2.13 \\
Point 2 & 5.62 & 1.01 & 93.3 & 0.06 & 0.00 & 0.00 \\
\hline
\end{tabular}

could also rotate and slide and result in micro-grooves in the A6061 component. Therefore, the combination of $\mathrm{SiO}_{2}$ particles and WC debris could be responsible for the formation of the grooves in the A6061 component. Therefore, since the delamination related to the adhesive mechanism and grooves are indicative of an abrasive mechanism, wear mechanism of the A6061 component could be considered as simultaneous occurrence of adhesive and abrasive mechanism. Moreover, it could be also concluded that the dominant damage of the cladding layer came from the soft A6061 component, which was the main source of delamination and the abrasive damage or removal of material during wear test. Therefore, one of the effective methods to improve wear resistance was to decrease the amount of the A6061 component in the cladding layer.

Under higher pressure $(P=23.5 \mathrm{~N})$, there were more WC debris stripped from the WC particles and thereby decreased their effectiveness as load support component to protect the other components. The grooves became larger and deeper on the surface of SHA particles. At the same 
time, the increased fractured WC debris was trapped in A6061 component to induce more severe damages. Therefore, as the load increased, the improvement of wear resistance decreased for all samples. On the other hand, the $\mathrm{FeAl}_{3}$ disappeared at the bottom of the cladding layer, which meant that the cladding layer lost the protection of $\mathrm{FeAl}_{3}$. This could explain the reason that the improvement of the wear resistance was minor at higher load, which was different from the other study [28].

From the results above, the wear mechanism of the cladding layer could be classified as adhesion, abrasive mechanisms and slight brittle failure. Moreover, the improvement of the wear resistance could be attributed to the following reasons: (1) The WC particles with high hardness acted as reinforcement against the abrasive $\mathrm{SiO}_{2}$ particles and protected the cladding layer from wear damage. (2) The formation of the $\mathrm{FeAl}_{3}$ was beneficial in reducing the wear damage. (3) The SHA particles played a role as binder material to balance the molting point and resistance between A6061 and WC to guarantee the formation of the cladding layer and acted as another reinforcement to improve the wear resistance. Furthermore, it also indicated that finding out the balance of the amount of the WC particles, $\mathrm{FeAl}_{3}$ and $\mathrm{A} 6061$ in the cladding layer was an effective method to further improve the wear resistance of the cladding layer.

\section{Conclusions}

(1) The cermet/iron cladding layers with good wear resistance on A6061 substrate were successfully fabricated by resistance seam welding with WC and SHA powders, which consisted of the WC reinforcement, SHA binder, $\mathrm{A} 6061$ and $\mathrm{FeAl}_{3}$ phases.

(2) Wear resistance of A6061 plate coated with the cladding layer was improved to about 3.5-5 times more than the uncovered A6061 substrate. At lower load, wear resistance increased with the decrease in the WC ratio. At higher load, the amount of WC was the dominant factor for the improvement of wear resistance.

(3) The molten A6061 in the cladding layer was the dominant damage material and the WC powders acted as reinforcement to protect the alloy surface from wearing. Furthermore, the SHA powders and $\mathrm{FeAl}_{3}$ also played important roles in decreasing the wear rate of the cladding layers. The wear damages of the cladding layer were adhesion, abrasive and a slight brittle failure.

\section{References}

[1] Y.Y. Xiong, N. Li, H.W. Jiang, Z.G. Li, Z. Xu, L. Liu, Acta Metall. Sin. (Engl. Lett.) 27, 272 (2014)

[2] S. Nath, S. Pityana, J.D. Majumdar, Surf. Coat. Technol. 206, 3333 (2012)

[3] Y.C. Chuang, S.C. Lee, H.C. Lin, Mater. Trans. 47, 1140 (2006)

[4] H.C. Man, S. Zhang, F.T. Cheng, Mater. Lett. 61, 4058 (2007)

[5] J.W. Lee, K. Nishio, M. Katoh, T. Yamaguchi, K. Mishima, Weld. World 49, 94 (2005)

[6] J.S. Xu, X.C. Zhang, F.Z. Xuan, F.Q. Tian, Z.D. Wang, S.T. Tu, Mater. Sci. Eng. A 560, 744 (2013)

[7] A.K. Basak, J.-P. Celis, M. Vardavoulias, P. Matteazzi, Surf. Coat. Technol. 206, 3508 (2012)

[8] X.Q. Zhao, H.D. Zhou, J.M. Chen, Mater. Sci. Eng. A 431, 290 (2006)

[9] X. Tong, F.H. Li, M. Kuang, W.Y. Ma, X.C. Chen, M. Liu, Appl. Surf. Sci. 258, 3214 (2012)

[10] L. He, Y.F. Tan, X.L. Wang, H. Tan, C.H. Zhou, Surf. Coat. Technol. 244, 123 (2014)

[11] A. Farid, S.J. Guo, Acta Mater. 55, 1467 (2007)

[12] P.H. Chong, H.C. Man, T.M. Yue, Surf. Coat. Technol. 145, 51 (2001)

[13] Y. Tanaka, M. Kajihara, Mater. Sci. 45, 5676 (2010)

[14] A. Bouayad, Ch. Gerometta, A. Belkebir, A. Ambari, Mater. Sci. Eng. A 363, 53 (2003)

[15] Z.M. Shi, J.B. Cao, F.S. Han, J. Nucl. Mater. 447, 77 (2014)

[16] K.A. Nazari, S.G. Shabestari, J. Alloys Compd. 478, 523 (2009)

[17] H.R. Shahverdi, M.R. Ghomashchi, S. Shabestari, J. Hejazi, J. Mater. Proc. Technol. 124, 345 (2002)

[18] W.H. Zhang, D.Q. Sun, L.J. Han, W.Q. Guo, X.M. Qiu, ISIJ Int. 51, 1870 (2011)

[19] H.J. Cheng, C.J. Wang, Appl. Surf. Sci. 277, 139 (2013)

[20] D.Q. Wang, Z.Y. Shi, L.J. Zou, Appl. Surf. Sci. 214, 304 (2003)

[21] J.X. Gong, T.S. Tang, Y.F. Xiao, Acta Metall. Sin. (Engl. Lett.) 23, 439 (2010)

[22] C.J. Li, H.T. Wang, G.J. Yang, C.G. Bao, J. Therm. Spray Technol. 20, 227 (2011)

[23] V. Abouei, H. Saghafian, S.G. Shabestari, M. Zarghami, Mater. Des. 31, 3518 (2010)

[24] F. Gao, H.M. Wang, Mater. Charact. 59, 1349 (2008)

[25] S. Seth, A.H. Jones, O.D. Lewis, Wear 302, 972 (2013)

[26] Y. Luo, L. Yang, M.C. Tian, S.R. Ge, Q.L. Wang, Mech. Eng. 227, 845 (2013)

[27] O.N. Çelik, Appl. Surf. Sci. 274, 334 (2013)

[28] H.R. Zafarani, M. Abdi, M.E. Bahrololoom, Acta Metall. Sin. (Engl. Lett.) 27, 347 (2014) 